\title{
Assignment of Human Erythroid $\delta$-Aminolevulinate Synthase (ALAS2) to a Distal Subregion of Band Xp11.21 by PCR Analysis of Somatic Cell Hybrids Containing $X$; Autosome Translocations
}

\author{
Philip D. Cotter, ${ }^{*}$ Huntington F. Willard, $†$ Jerome L. Gorski, $†$ And David F. Bishop* 1 \\ *Division of Medical and Molecular Genetics, Mount Sinai School of Medicine, Fifth Avenue and 100th Street, New York, New York \\ 10029; †Department of Genetics, Stanford University School of Medicine, Stanford, California 94305; and \\ $\ddagger$ Department of Pediatrics, University of Michigan Medical Center, Ann Arbor, Michigan 48109
}

Received October 25, 1991

\begin{abstract}
The erythroid-specific (ALAS2) and housekeeping (ALAS1) genes encoding $\delta$-aminolevulinate synthase have recently been mapped to chromosomes Xp21.1 $\rightarrow$ q21 and 3p21, respectively. The erythroid-specific gene is a candidate for mutations resulting in X-linked sideroblastic anemia. Analysis of DNA from hybrid clones containing translocations in the re-

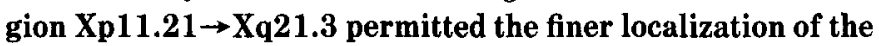
ALAS2 gene with respect to other loci and breakpoints within this region. These studies localized the ALAS2 gene to the distal subregion of Xp11.21 in Interval 5 indicating the following gene order: Xpter-OATL2-[L62-3A, Xp11.21; A62-1A4b, Xp11.21]-(ALAS2, DXS323)-[B13-3, Xp11.21; C9-5, Xp11.21]-(DXS14, DXS429)-DXS422-(DXZ1, Xcen). Thus, the reported linkage of acquired sideroblastic anemia and sideroblastic anemia with ataxia to Xq13 presumably results from genes other than ALAS2. 1992 Academic Press, Inc.
\end{abstract}

$\delta$-Aminolevulinate synthase [Succinyl-CoA:glycine $C$ succinyltransferase (decarboxylating); EC 2.3.1.37, (ALAS)] catalyzes the first committed step in heme biosynthesis. The erythroid-specific gene (ALAS2) has been mapped to the $X$ chromosome (2) and localized to $\mathrm{Xp21.1 \rightarrow q21}$ (3). This localization makes ALAS2 a candidate gene for mutations resulting in X-linked sideroblastic anemia $(2,3)$, consistent with the decreased ALAS activity commonly found in patient's bone marrow (1). Indeed, the first report of a mutation of ALAS2 in a case of pyridoxine-responsive X-linked sideroblastic anemia (Cotter et al., in press) demonstrates the association between ALAS2 and this disease. However, Raskind et al. (7) reported the linkage of X-linked sideroblastic anemia with ataxia to $\mathrm{Xq} 13$, and Dewald $e t$ al. (4) found chromosomal rearrangements involving $\mathrm{Xq13}$ in selected patients with idiopathic acquired sideroblastic anemia. In this report, a somatic cell hybrid panel of X;autosome translocations has permitted a finer localization of ALAS2 to the specific subregion Xp11.21.

The somatic cell hybrid panel used to dissect the re-

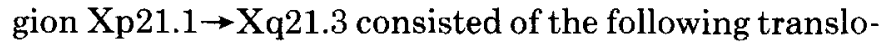

\footnotetext{
${ }^{1}$ To whom correspondence should be addressed.
}

cation clones: A2-4, Xp21.1 $\rightarrow$ Xqter; DUA-1CsAzB, $\mathrm{Xpter} \rightarrow \mathrm{Xp11.22;}$ I.62-3A, Xpter $\rightarrow \mathrm{Xp11.21;} \mathrm{A62-1A-}$ $4 \mathrm{~b}, \quad \mathrm{Xp11.21} \rightarrow$ Xqter; A48-1Fa, Xcen $\rightarrow$ Xqter; A63$1 \mathrm{~A}, \mathrm{Xq11.2 \rightarrow Xqter;}$ A68-2A, Xq13 $\rightarrow$ Xqter; W4-1A, $\mathrm{Xq13} \rightarrow$ Xqter; A50-1Acl.3A, Xq21.3 $\rightarrow$ Xqter (6) and B13-3, Xp11.21 $\rightarrow$ Xqter; C9-5, Xp11.21 $\rightarrow$ Xqter (5). None of these hybrid lines contained an intact X chromosome as assessed by polymerase chain reaction (PCR) analysis of the steroid sulfatase gene (STS) on $\mathrm{Xp} 22.32$ and the phosphoglycerate kinase gene (PGK1) on Xq13.3 ( $(8,9)$; Yen, GenBank Accession No. M16505). The PCR primer pair for STS (5'-TAATGA CGTATACATAGGCATCATTTCA-3' and 5'-CCACATTGTTGAATTGAGTCACGATAG-3') amplified a 335-bp fragment, and the PCR primers for PGK1 (5'-CTTAGCATTTTCTGCATCTCCACTTG- $3^{\prime}$ and 5'-CATGCTGAGTAGTGAAACAGTGACA-3') amplified a 312 -bp product. PCR primers for ALAS2 (5'GCCGCCGAATTCAAACTTGAATTTTCA'TG-3' and 5'-GCCGCCGAATTCGCCCTTCTGTACTGTTT-3'), amplified a 333-bp fragment encompassing exon 4 and flanking intronic sequences (Bishop et al., unpublished). The 100- $\mu \mathrm{l}$ PCR reaction mixture contained $1 \mu \mathrm{g}$ of DNA, $10 \mu$ of $10 \times$ Taq polymerase buffer, $50 \mu \mathrm{M}$ of each dNTP, 100 pmol each of the sense and antisense oligonucleotides, and 2.5 units of Taq polymerase (Promega, Madison, WI). The reaction mixture was incubated at $94^{\circ} \mathrm{C}$ for $6 \mathrm{~min}$, then 30 cycles of PCR amplification were performed with denaturation at $94^{\circ} \mathrm{C}$ for $1 \mathrm{~min}$, primer annealing at 60,68 , and $54^{\circ} \mathrm{C}$ for the STS, PGK1, and ALAS2 primers, respectively, for $1 \mathrm{~min}$, and extension at $72^{\circ} \mathrm{C}$ for $2 \mathrm{~min}$.

As illustrated in Fig. 1, clones A2-4, and A62-1A-4b (lanes 2 and 4, respectively) were positive for the ALAS2 gene. In particular, clones L62-3A, C9-5, and B13-3, which were ALAS2-negative (lanes 5,6 , and 7 , respectively), and ALAS2-positive clone A62-1A-4B localized ALAS2 to a narrow overlap region of Xp11.21 within Interval 5 (6). The remaining five clones with breakpoints in the region Xcen $\rightarrow \mathrm{q} 21.3$ were all ALAS2-negative and are not shown in Fig. 1. PCR analysis of the hybrid clones with exon 10 ALAS2 primers gave identi- 

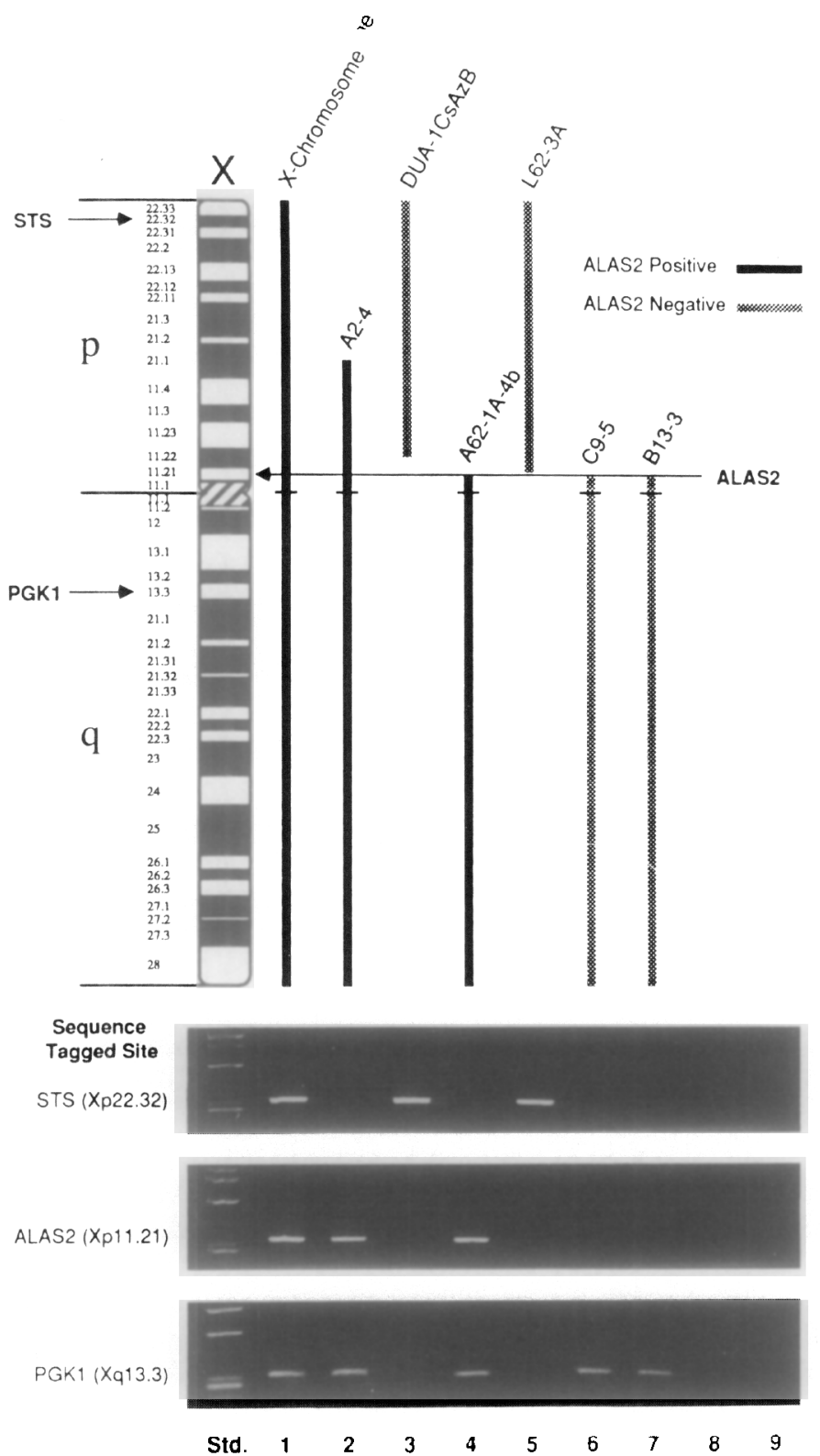

FIG. 1. Localization of ALAS2 to band Xp11.21 by PCR analysis of translocation hybrids. The three gel panels, showing ethidium bromide-stained $1.7 \%$ agarose gels, contain PCR products from the primer pairs for the STS, ALAS2, and PGK1 genes. The Std. lane contains $\phi$ X174 DNA digested with HaeIII. Lanes 1,8 and 9 contain human, Chinese hamster, and mouse genomic DNA, respectively. Lanes 2 through 7 contain DNA from the hybrid clones indicated in the diagram above the panels. The solid vertical bars indicate genomic DNA and hybrid clones positive for the ALAS2 gene, while the shaded bars indicate ALAS2-negative clones.

cal results (data not shown). PCR analyses of all hybrid clones with both $\mathrm{Xp}$ and $\mathrm{Xq}$ sequence-tagged sites demonstrated concordance with the published X chromosome breakpoints and the absence of complete X chromosomes (Fig. 1). These results confirm and extend the previous regional mapping (3) by confining the gene to a specific subregion of band Xp11.21.

Integration of these results with previous data on physical mapping, including Interval 5 of the pericentromeric region of the human $\mathrm{X}$ chromosome $(5,6)$, made it possible to refine the localization of ALAS2 with respect to other loci and breakpoints according to the order: Xpter-OATL2-[L62-3A, Xp11.21; A62-1A-4b, Xp11.21]-(ALAS2，DXS323)-[B13-3，Xp11.21; C9-5, Xp11.21]-(DXS14, DXS429)-DXS422-(DXZ1, Xcen). Thus, the ALAS2 locus and DXS323 are subregionally localized to the distal segment of Xp11.21, as defined by the incontinentia pigmenti-1 (IP-1) breakpoints within hybrid clones $\mathrm{B} 13-3$ and $\mathrm{C} 9-5$. The proximal segment of Xp11.21 presumably contains the IP-1 locus and additional loci as noted in Gorski et al. (5). The ordering of these loci relative to each other within Xp11.21 awaits further study. This mapping of ALAS2 to the distal subregion of $\mathrm{Xp11.21}$ also suggests that genes other than or in addition to ALAS2 are involved in the X-linked and idiopathic-acquired sideroblastic anemias associated with Xq13.

\section{ACKNOWLEDGMENTS}

The authors thank R. Lafrenière for expert assistance. This study was supported in part by Grants R01 DK40895 (D.F.B.), HG00013 (H.F.W.), and R01 HD23768 (J.L.G.) from the National Institutes of Health.

\section{REFERENCES}

1. Aoki, Y., Urata, G., Wada, O., and Takaku, F. (1974). Measurement of $\delta$-aminolevulinic acid synthetase activity in human erythroblasts. J. Clin. Invest. 53: 1326-1334.

2. Bishop, D. F., Henderson, A. S., and Astrin, K. H. (1990). Human $\delta$-aminolevulinate synthase: Assignment of the housekeep ing gene to $3 \mathrm{p} 21$ and the erythroid-specific gene to the $\mathrm{X}$ chromosome. Genomics 7: 207-214.

3. Cox, T. C., Bawden, M. J., Abraham, N. G., Bottomley, S. S., May, B. K., Baker, E., Chen, L. Z., and Sutherland, G. R. (1990). Erythroid 5-aminolevulinate synthase is located on the $\mathrm{X}$ chromosome. Am. J. Hum. Genet. 46: 107-111.

4. Dewald, G. W., Brecher, M., Travis, L. B., and Stupca, P. J. (1989). Twenty-six patients with hematologic disorders and $X$ chromosome abnormalities. Frequent idic $(X)(q 13)$ chromosomes and Xq13 anomalies associated with pathologic ringed sideroblasts. Cancer Genet. Cytogenet. 42: 173-185.

5. Gorski, J. L., Burright, E. N., Harnden, C. E., Stein, C. K., Glover, T. W., and Reyner, E. L. (1991). Localization of DNA sequences to a region within Xp11.21 between incontinentia pigmenti (IP1) X-chromosomal translocation breakpoints. Am. J. Hum. Genet. 48: 53-64.

6. Lafrenière, R. G., Rrown, C. J., Powers, V. E., Carrel, L., Davies, K. E., Barker, D. F., and Willard, H. F. (1991). Physical mapping of 60 DNA markers in the $\mathrm{p} 21.1 \rightarrow \mathrm{q} 21.3$ region of the human $\mathrm{X}$ chromosome. Genomics 11: 352-363.

7. Raskind, W. H., Wijsman, E., Pagon, R. A., Cox, T. C., Bawden, M. J., May, B. K., and Bird, T. D. (1991). X-linked sideroblastic anemia and ataxia: Linkage to phosphoglycerate kinase at Xq13. Am. J. Hum. Genet. 48: 335-341.

8. Theune, S., Fung, J., Todd, S., Sakaguchi, A. Y., and Naylor, S. L. (1991). PCR primers for human chromosomes: Reagents for the rapid analysis of somatic cell hybrids. Genomics 9: 511516.

9. Verga, V., Hall, B. K., Wang, S., Johnson, S., Higgins, J. V., and Glover, T. W. (1991). Localization of the translocation breakpoint in a female with Menkes syndrome to Xq13.2-q13.3 promixal to PGK-1. Am. J. Hum. Genet. 48: 1133-1138. 